Patricia A. Kapur MD,

Evelyn J. Norel MBBS FFARCS,

Himmet Dajee MD, Gary Cohen BS, Werner Flacke MD

\title{
Haemodynamic effects of verapamil administration after large doses of fentanyl in man
}

Thirteen patients with good left ventricular function undergoing coronary artery revascularization were studied to determine the cardiovascular effects of verapamil, $75-150 \mu \mathrm{g} \cdot \mathrm{kg}^{-1}$, after a large dose $\left(100 \mu \mathrm{g} \cdot \mathrm{kg}^{-1}\right)$ of fentanyl, with pancuronium for muscle relaxation. The patients were continued on their usual cardiovascular medications until the time of surgery, which included nitrates, beta adrenergic blockers, and nifedipine. Anaesthesia with fentanyl was associated with decreases in mean arterial blood pressure, systemic vascular resistance, left ventricular stroke work index, and circulating catecholamine levels. Mean values were not further changed by verapamil, but individual patients had additional modest decreases in blood pressure and systemic vascular resistance. Cardiac index, however, was well maintained. Plasma catecholamines remained depressed after verapamil under the study condition. Thus, in patients with good left ventricular function, clinically relevant doses of verapamil were well tolerated even in the presence of an anaesthetic that included large doses of fentanyl, with suppression of circulating catecholamine levels.

\section{Key words}

ANALGESICS: fentanyl; ANAESTHETICS, intravenous; PHARMACOLOGY: verapamil; SYMPATHETIC NERvOUS SYSTEM: anaesthesia, catecholamine levels.

From the Anesthesiology and Surgery Services, Veterans Administration Medical Center, West Los Angeles, Califomia, and the Departments of Anesthesiology and Surgery; UCLA School of Medicine, Los Angeles, California.

Address correspondence to: Dr. Kapur, Department of Anesthesiology, UCLA School of Medicine, Center for the Health Sciences, Los Angeles, California 90024.
Large doses of fentanyl $\left(50-100 \mu \mathrm{g} \cdot \mathrm{kg}^{-1}\right)$ are commonly employed to preserve haemodynamic stability and to suppress stress hormone responses during cardiac surgery. ${ }^{1-4}$ The interactions of large doses of narcotics with the effects of various calcium channel blockers have been little explored, yet the acute administration of verapamil may be indicated perioperatively for the immediate control of supraventricular arrhythmias. ${ }^{5.6}$ In the clinical setting, the perioperative management of patients with coronary artery disease frequently includes nitrates, beta blockers, and/or nifedipine in addition to anaesthetic agents. Results obtained in awake patients in the cardiac catheterization laboratory may bear little resemblance to conditions encountered in anaesthetized patients during cardiac surgery.

While additive haemodynamic depression has been described when verapamil has been administered during inhalation anaesthesia in animals and man, ${ }^{7-9}$ few studies have been done during anaesthesia with large doses of narcotics. While direct myocardial effects of large doses of fentanyl are minimal, its sympatholytic properties associated with depression of circulating catecholamine levels may result in significant peripheral vasodilation. ${ }^{10}$ The often benign haemodynamic effects of calcium channel blockers in intact unanaesthetized subjects, however, are partially a result of autonomically mediated compensatory responses to the direct cardiovascular depressant effects of these drugs. ${ }^{11}$

The question of whether modulation of autonomic responsiveness by large doses of narcotics will lead to unacceptable haemodynamic depression upon the subsequent administration of verapamil has not been fully addressed. Zimpfer et al. ${ }^{12}$ gave verapamil, $70 \mu \mathrm{g} \cdot \mathrm{kg}^{-1}$, to patients after small doses of fentanyl and noted transiently decreased blood 
TABLE Characteristics of patients

\begin{tabular}{|c|c|c|c|c|c|c|c|}
\hline Patient & $\begin{array}{l}\text { Age } \\
(y r)\end{array}$ & $\begin{array}{l}\text { Propranolol } \\
\text { dose } \\
(m g / d a y)\end{array}$ & $\begin{array}{l}\text { Plasma } \\
\text { propranolol } \\
\text { level } \ddagger \\
\left(n g \cdot \mathrm{ml}^{-1}\right)\end{array}$ & $\begin{array}{l}\text { Nifedipine } \\
\text { dose } \\
\text { (mg/day) }\end{array}$ & $\begin{array}{l}L V \\
\text { ejection } \\
\text { fraction } \\
(\%)\end{array}$ & $\begin{array}{l}\text { Previous } \\
\text { myocardial } \\
\text { infarction }\end{array}$ & $\begin{array}{l}\text { Number of } \\
\text { vessels } \\
\text { revascularized }\end{array}$ \\
\hline 1 & 52 & 720 & 362 & 30 & 74 & + & 4 \\
\hline 2 & 65 & $*$ & - & - & 54 & + & 2 \\
\hline 3 & 59 & - & - & 30 & 60 & - & 3 \\
\hline 4 & 43 & 160 & 25 & - & 65 & + & 4 \\
\hline 5 & 61 & 80 & 55 & 120 & 60 & + & 4 \\
\hline 6 & 47 & - & - & - & 54 & + & 2 \\
\hline 7 & 44 & 320 & 273 & 90 & 50 & + & 3 \\
\hline 8 & 39 & 80 & 7 & 60 & 40 & + & 4 \\
\hline 9 & 50 & 240 & 12 & - & 65 & - & 4 \\
\hline 10 & 61 & 160 & 136 & 90 & - & + & 2 \\
\hline 11 & 49 & 240 & 189 & 45 & 70 & + & 2 \\
\hline 12 & 37 & - & - & 30 & 60 & + & 3 \\
\hline 13 & 47 & 80 & 36 & - & 50 & - & 5 \\
\hline mean $\pm \mathrm{SE}$ & $50 \pm 2$ & $231 \pm 67$ & $122 \pm 43$ & $62 \pm 12$ & $54 \pm 3$ & & $3.2 \pm 0.3$ \\
\hline
\end{tabular}

*Atenolol, $25 \mathrm{mg}$ daily; $¥$ at the time of awake measurements.

pressure and peripheral resistance with well maintained cardiac output. Kates and Kaplan ${ }^{13}$ administered verapamil, $75 \mu \mathrm{g} \cdot \mathrm{kg}^{-1}$, to patients undergoing coronary artery surgery who were anaesthetized with morphine, nitrous oxide, and diazepam. The verapamil was not given until after the aorta was cannulated, the doses of morphine and diazepam varied three-fold, and the intervals since the last narcotic doses may have varied. Nevertheless, they observed decreased blood pressure after verapamil associated with decreased mean systemic vascular resistance and left ventricular stroke work index, and a prolonged mean PR interval of the ECG.

The present study was designed to systematically evaluate the cardiovascular effects of recommended therapeutic doses of verapamil given to patients after the initiation of a clinically relevant anaesthetic that included a large dose of fentanyl at a time when plasma fentanyl levels would likely be high. Plasma verapamil and propranolol levels were measured as well as circulating epinephrine and norepinephrine levels.

\section{Methods}

After approval by the institutional Human Studies Committee and after giving their informed consent, thirteen patients scheduled for elective coronary artery bypass surgery were entered into the study. Patient characteristics are shown in the Table. All patients had left ventricular (LV) ejection fractions greater than 0.40 and were in sinus rhythm with $P R$ intervals on the preoperative ECG of less than 0.20 seconds. The study patients had no history of heart failure and were taking neither digoxin nor verapamil preoperatively. All patients were taking nitrates. Nine patients were on chronic oral propranolol therapy with a mean \pm SE daily dose of $231 \pm$ $67 \mathrm{mg}$. One patient was taking atenolol, $25 \mathrm{mg}$ daily. Eight patients were taking nifedipine with a mean daily dose of $62 \pm 12 \mathrm{mg}$. All cardiac medications were continued through the morning of surgery.

Premedication was with diazepam, $10 \mathrm{mg}$ orally. All patients had two venous cannulas, radial arterial catheters, and balloon-tipped pulmonary artery catheters in place for the study. Prior to anaesthesia, the patients breathed 100 per cent oxygen by face mask. Continuous recordings were then made of the ECG; systolic, diastolic and mean arterial pressure (MAP); right atrial (RA); and pulmonary artery (PA) pressures. Intermittent measurements were taken of pulmonary capillary wedge (PCW) pressures and of the ECG limb lead II, at $50 \mathrm{~mm} \cdot \mathrm{s}^{-1}$ for measurement of PR intervals at control and at the study intervals detailed subsequently. Cardiac output determinations were made in triplicate by thermodilution. Systemic vascular resistance (SVR) was calculated as [(MAP-RA)/CO]80, pulmonary vas- 


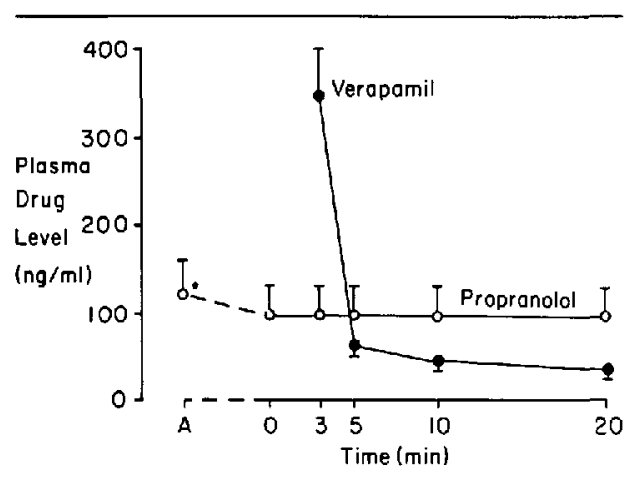

FIGURE 1 Plasma levels of verapamil and propranolol when the study subjects were awake $(A)$, after being anaesthetized (time 0 ), and at subsequent times after the start of the 2-min verapamil infusion. Mean $\pm \mathrm{SEM}, *=p<0.05$ compared to time 0 .

cular resistance (PVR) as [(mean PA-PCW)/CO]80, cardiac index $(\mathrm{CI})$ as (CO/body surface area), and $\mathrm{LV}$ stroke work index (LVSWI) as [(CI $\times$ MAP) 13.6]/ HR. Arterial samples were taken for blood gases, and for plasma verapamil, propranolol, norepinephrine (NE) and epinephrine (EPI) levels, which were assayed by high performance liquid chromatography. ${ }^{14,15}$ Temperature was measured throughout.

Anaesthesia consisted of intravenous diazepam, 10-15 mg, and pancuronium, $1 \mathrm{mg}$, intravenously, followed by fentanyl $100 \mu \mathrm{g} \cdot \mathrm{kg}^{-1}$ by continuous infusion over $20 \mathrm{~min}$. An additional $9 \mathrm{mg}$ of pancuronium was administered at loss of the lid reflex followed by controlled ventilation $\left(\mathrm{F}_{1} \mathrm{O}_{2}=1.0\right)$. Intubation of the trachea occured $7 \pm 1$ min after beginning the $20 \mathrm{~min}$ fentanyl infusion. Immediately after completion of the fentanyl infusion, haemodynamic measurements and plasma samples were again taken. Verapamil, $75(\mathrm{n}=8)$ or $150(\mathrm{n}=5) \mu \mathrm{g} \cdot \mathrm{kg}^{-1}$, was then infused over two minutes. Repeat cardiovascular measurements and plasma samples were taken $3,5,10$ and $20 \mathrm{~min}$ after starting the verapamil infusion. Bladder catheterization and surgical preparation were withheld until after the study was completed.

Analysis of variance for repeated measures with Bonferroni t-tests were used to compare values from other times to the measurements taken immediately after completion of the fentanyl infusion before starting verapamil. Regression equations with calculations of correlation coefficients were used to

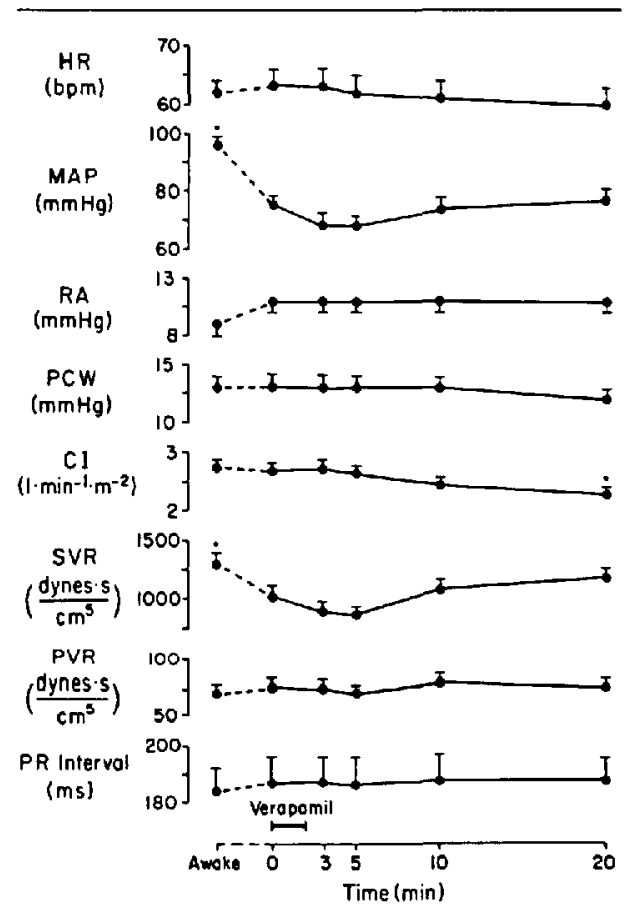

FIGURE 2 Cardiovascular values when the study subjects were awake (A), after being anesthetized (time 0 ), and at subsequent times after the start of the 2-min verapamil infusion. Mean $\pm \mathrm{SEM}, *=\mathrm{p}<0.05$ compared to time 0 .

evaluate correlations between variables. A p value of less than 0.05 was considered significant.

\section{Results}

Arterial blood gases were within normal limits and temperature remained constant throughout all phases of the study. Changes in mean plasma verapamil and propranolol levels are shown in Figure 1. Propranolol levels decreased slightly with the initiation of anaesthesia, but remained constant thereafter. There was no difference in cardiovascular variables between the patients receiving either dose of verapamil when measured prior to anaesthesia, after fentanyl, or after the bolus of verapamil, thus the results were combined in the table and the figures.

Mean cardiovascular measurements are plotted in Figure 2. The anaesthetic combination of fentanyldiazepam-pancuronium significantly reduced SVR and MAP with no change in heart rate. Compared to immediate post-fentanyl values, the administration 


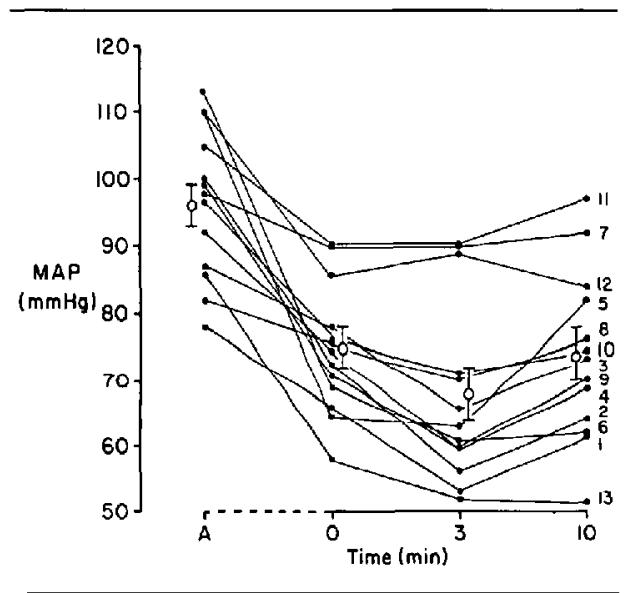

FIGURE 3 Changes in mean arterial pressure (MAP) for individual patients (patient numbers on right comelate with the Table). Values when awake (A), unaesthetized (time 0 ), and 3 and 10 min after starting the verapamil infusion are shown.

of a single dose of verapamil did not result in further decreases in the means of the systemic vascular resistance and mean arterial pressure. However, individual changes in MAP and SVR are plotted in Figures 3 and 4, with additional decreases in MAP and SVR seen in a number of patients after verapamil.

The MAP of patients 1, 2, 6 and 13 remained below 65 torr even $10 \mathrm{~min}$ after verapamil administration. No discernable difference could be determined in these patients regarding their preoperative status or chronic medications (Table). Three of those four patients received $150 \mu \mathrm{g} \cdot \mathrm{kg}^{-1}$ of verapamil while the other received the $75 \mu \mathrm{g} \cdot \mathrm{kg}^{-1}$ dose. Three of the four had an SVR less than 800 dynes $\cdot \mathrm{sec} \cdot \mathrm{cm}^{-5}$ after the anesthetic induction. The change in SVR for all patients correlated with the change in MAP for both the administration of fentanyl $(y=0.03 x-12.8$; $r=0.66 ; n=13 ; p=0.014$ ), as well as the subsequent administration of verapamil $(y=0.05 x-$ 1.6; $\mathrm{r}=0.79 ; \mathrm{n}=13 ; \mathrm{p}=0.002$ ). There was a significant decrease in norepinephrine level after fentanyl administration from $244 \pm 18$ to $104 \pm$ $23 \mathrm{pg} \cdot \mathrm{ml}^{-1}$, without further change after verapamil. In all but one patient plasma epinephrine levels fell to below the lower limits of the assay $\left(20 \mathrm{pg} \cdot \mathrm{ml}^{-1}\right)$ after the anaesthetic with no further change after verapamil. In patient 7 , the epinephrine level rose from 43 to $153 \mathrm{pg} \cdot \mathrm{ml}^{-1}$ after the anaesthetic induc-

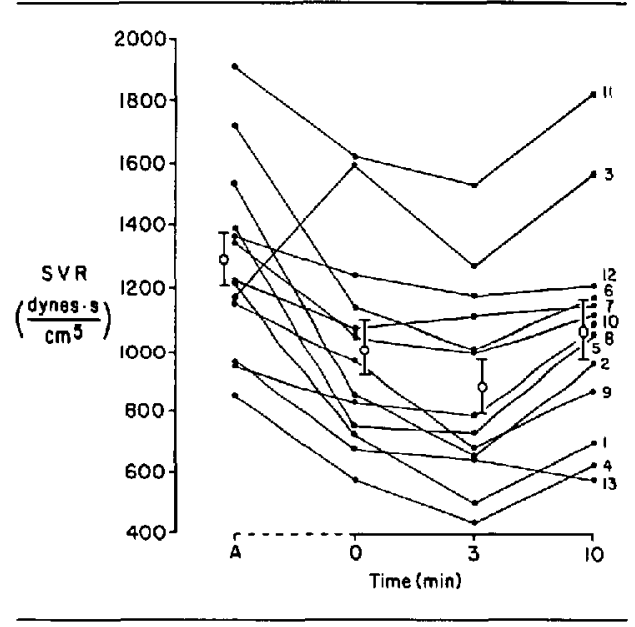

FIGURE 4 Changes in systemic vascular resistance (SVR) for individual patients (patient numbers on right correlate with the Table). Values when awake $(A)$, anaesthetized (time 0 ), and 3 and $10 \mathrm{~min}$ after starting the verapamil infusion are shown.

tion and stayed in that range after verapamil administration. The magnitude of both the preanaesthetic epinephrine level as well as the change in epinephrine level were correlated with the magnitude of the decrease in MAP that occurred with fentanyl administration. (Pre-anaesthetic EPI vs. $\Delta \mathrm{MAP}_{\text {fentanyl }}: \mathrm{y}=-0.26 \mathrm{x}-9.3, \mathrm{r}=0.76, \mathrm{n}=13$, $\mathrm{p}=0.003 ; \Delta \mathrm{EPI}_{\text {fentanyl }}$ vs. $\Delta \mathrm{MAP}_{\text {fentanyl }}: \mathrm{y}=$ $0.15 \mathrm{x}-18.8, \mathrm{r}=0.63, \mathrm{n}=13, \mathrm{p}=0.019$.)

Changes in MAP and SVR were not correlated with the initial norepinephrine level or with propranolol levels. Propranolol levels were also not correlated with pre-anaesthetic values for heart rate for the group as a whole. (Individual dose response curves for HR vs. propranolol level were not evaluated.) In a similar manner measured verapamil levels did not correlate with the magnitude of changes in MAP or SVR in the group as a whole, though recovery of blood pressure with time as verapamil levels waned indicated a general dose response relationship.

Mean CI was unchanged by fentanyl or immediately after verapamil administration except for a slight decrease compared to the post-fentanyl value observed $20 \mathrm{~min}$ after verapamil was given. At that time, SVR and MAP were equal to post-fentanyl values. There were no significant changes in mean 
PR interval, RA or PCW pressures, or PVR throughout this study. Mean LVSWI was significantly decreased from $58 \pm 3$ to $44 \pm 3 \mathrm{~g} \cdot \mathrm{m} \cdot \mathrm{m}^{-2}$ after fentanyl administration without further significant change when verapamil was subsequently given.

\section{Discussion}

The administration of verapamil caused no to modest additional changes in these patients with good left ventricular function undergoing coronary artery revascularization, in the presence of large doses of fentanyl, and with continuation of chronic medications including beta-blockers and nifedipine until the time of operation. Vasodilation and decreased blood pressure occurred with this type of anaesthetic, consistent with the findings of other investigators. ${ }^{16}$ However, cardiac index was well preserved at a lower level of myocardial work as heart rate was unchanged and afterload decreased.

Though we did not have the capability to assay plasma fentanyl concentrations, given the known pharmacokinetics of fentanyl, ${ }^{17}$ there was a high likelihood of effective plasma fentanyl concentrations persisting for the duration of our study. A plasma fentanyl level of $20 \mathrm{ng} \cdot \mathrm{ml}^{-1}$ has been found to result in haemodynamic stability during the surgical stresses prior to cardiopulmonary bypass. ${ }^{18}$ Lunn et al. ${ }^{1}$ administered fentanyl $75 \mu \mathrm{g} \cdot \mathrm{kg}^{-1}$ over 15 minutes and found the mean as well as one standard deviation of the plasma fentanyl level to be above $20 \mathrm{ng} \cdot \mathrm{ml}^{-1}$ for at least 60 minutes. Our patients received $100 \mu \mathrm{g} \cdot \mathrm{kg}^{-1}$ and our study was completed approximately $40 \mathrm{~min}$ after starting fentanyl.

In every patient the major change in blood pressure was associated primarily wth the vasodilation resulting from the anaesthetic, which is consistent with the findings of Tomichek et al. who investigated the combination of fentanyl with small amounts of diazepam. ${ }^{16}$ Thus, further changes in the means of the MAP values after verapamil were small in comparison, and not significant when analysis of variance for repeated measures was applied to all of the data points. However, individual patients had decreases in MAP of up to $17 \mathrm{mmHg}$ after verapamil, and as previously mentioned, lower MAP values persisted for $10 \mathrm{~min}$ in several patients. It is possible that the prior administration of pancuronium, which is known to have effects on the autonomic nervous system ${ }^{19,20}$ may have mitigated some of the effects of the other drugs subsequently administered during the study on heart rate and cardiac output.

The lack of correlation of haemodynamic response to verapamil with plasma propranolol levels in our patients was somewhat surprising given the known potential adverse effects of combined beta adrenergic antagonists and slow calcium channel inhibitors in man. ${ }^{21}$ Physiological effects of beta antagonists have been noted with plasma propranolol levels of greater than $10 \mathrm{ng} \cdot \mathrm{ml}^{-1}$, with marked diminution of the heart rate response to exercise at propranolol plasma levels of $100 \mathrm{ng} \cdot \mathrm{ml}^{-1}$. ${ }^{22}$ This may indicate that additional factors contribute to the net interaction of beta blockers with calcium channel blockers, for example, presence of active metabolites, differences in plasma drug binding, or individual variations in receptor sensitivity.

Since fentanyl has no apparent direct myocardial depressant effects, theoretical considerations for an adverse interaction of this anaesthetic combination with calcium channel blockers include additive vasodilation and secondary effects resulting from suppression of circulating catecholamine levels. The latter may result in an impaired autonomic compensatory reserve for the direct depressant effects of verapamil. The correlation of blood pressure response to fentanyl with initial plasma epinephrine levels has been demonstrated in a canine model. ${ }^{10}$ In the present study we were able to note a similar phenomenon in man and to show that the greater the decrease in plasma epinephrine level caused by fentanyl, the greater the concomitant decrease in blood pressure.

The presence of presumed high plasma levels of fentanyl and documented suppression of circulating epinephrine and norepinephrine levels, under the conditions of this study, were not associated per se with untoward effects following verapamil in our patients with good left ventricular function. Even when blood pressure decreased following the bolus dose, the decrease was generally transient and cardiac output was well maintained in all of our patients. Nevertheless, individual variation in preexisting autonomic tone and response to anaesthetics must be anticipated and may alter the response to verapamil. Despite adquate cardiac output, lowered perfusion pressures after a dose of verapamil, such as the $150 \mu \mathrm{g} \cdot \mathrm{kg}^{-1}$ used in this study, may jeopardize regional perfusion in patients with widespread vascular disease. In addition, a fentanyl-based 
anaesthetic is frequently chosen for patients with decreased left ventricular function, a group in whom verapamil is usually less well tolerated even in the absence of anaesthetics. ${ }^{23}$ In clinical practice, therefore, the results of our study would suggest that lower doses of verapamil be titrated to the clinically desired effect in the perioperative period in patients undergoing an anaesthetic that includes a large dose of fentanyl.

\section{References}

1 Lunn JK, Stanley TH, Eisele J, Webster L, Woodward $A$. High does fentanyl anesthesia for coronary artery surgery: plasma fentanyl concentrations and influence of nitrous oxide on cardiovascular responses. Anesth Analg 1979; 58: 390-5.

2 Stanley TH, Berman L, Green O, Robertson D. Plasma catecholamine and cortisol responses to fentanyl-oxygen anesthesia for coronary-artery operations. Anesthesiology 1980; 53: 250-3.

3 Zurick AM, Urzua J, Yared J.P, Estafanous FG. Comparison of hemodynamic and hormonal effects of large single-dose fentanyl anesthesia and halothane/ nitrous oxide anesthesia for coronary artery surgery. Anesth Analg 1982; 61: 521-6.

4 Wynands JE, Townsend GE, Wong $P$, Whalley $D G$, Srikant CB, Patel YC. Blood pressure response and plasma fentanyl concentrations during high- and very high-dose fentanyl anesthesia for coronary artery surgery. Anesth Analg 1983; 62: 661-5.

5 Waxman HL, Myerburg RJ, Appel R, Sung RJ. Verapamil for control of ventricular rate in paroxysmal supraventricular tachycardia and atrial fibrillation or flutter. Ann Intern Med 1981; 94: 1-6.

6 Plumb VJ, Karp RB, Kouchoukos NT, Zorn GL Jr, James $T N$, Walto $A L$. Verapamil therapy of atrial fibrillation and atrial flutter following cardiac operation. J Thorac Cardiovasc Surg 1982; 83: 590-6.

7 Kapur PA, Flacke WE. Epinephrine-induced arrhythmias and cardiovascular function after verapamil during halothane anesthesia in the dog. Anesthesiology 1981; 55: 218-25.

8 Kates RA, Kaplan JA, Guyton RA, Dorsey L, Hug $C C$, Hatcher $C B$. Hemodynamic interactions of verapamil and isoflurane. Anesthesiology 1983; 59: 132-8.

9 Schulte-Sasse U, Hess W, Markschies-Hornung A, Tarnow $J$. Combined effects of halothane anesthesia and verapamil on systemic hemodynamics and left ventricular myocardial contractility in patients with ischemic heart disease. Anesth Analg 1984; 63:

791-8.

10 Flacke JW, Flacke WE, Bloor B C, Olewine S. Effects of fentanyl, naloxone and clonidine on hemodynamics and plasma catecholamine levels in dogs. Ancsth Analg 1983; 62: 305-13.

11 Antman EM, Stone PH, Muller JE, Braunwald E. Calcium channel blocking agents in the treatment of cardiovascular disorders. Part I: Basic and clinical electrophysiological effects. Ann Intern Med 1980; 93: 875-85.

12 Zimpfer M, Fitzal S, Tonczar L. Verapamil as a hypotensive agent during neuroleptanaesthesia. Br J Anaesth 1981; 53: 885-9.

13 Kates RA, Kaplan JA. Cardiovascular responses to verapanil during coronary artery bypass graft surgery. Anesth Analg 1983; 62: 821-6.

14 Watson E, Kapur PA. High-performance liquid chromatographic determination of verpamil in plasma by fluorescence detection. J. Pharm Sci 1981; 70: $800-1$.

15 Watson $E$, Liquid chromatography with electrochemical detection for plasma norepinephrine and epinephrine. Life Sci 1981; 28: 492-7.

16 Tomicheck RC, Rosow CE, Philbin DM, Moss $J$, Teplick RS, Schneider RC. Diazepam-fentanyl interaction - hemodynamic and hormonal effects in coronary artery surgery. Anesth Analg 1983; 62: 881-4.

17 MCClain DA, Hug CC. Intravenous fentanyl kinetics. Clin Pharmacol Ther 1980; 28: 106-14.

18 Moldenhauer CC, Hug CC Jr. Continuous infusion of fentanyl for cardiac surgery. (Abstract) Anesth Analg 1981; 61: 206.

19 Saxena PR, Bonta $I L$. Mechanism of selective cardiac vagolytic action of pancuronium bromide. Selective blockade of cardiac muscarinic receptors. Eur J Pharmacol 1970; 11: 322-41.

20 Ivankovich $A D$, Miletich DJ, Albrecht RF, Zahed B. The effect of pancuronium on myocardial contraction and catecholamine metabolism. J Pharm Pharmacol 1975; 27: 837-41.

21 Packer M, Meller J, Medina N et al. Hemodynamic consequences of combined beta-adrenergic and slow calcium channel blockade in man. Circulation $1982 ; 65: 660-8$.

22 Mullane JF, Kaufman J, Dvornik D, Coelho J. Propranolol dosage, plasma concentration, and beta blockade. Clin Pharmacol Ther 1982; 32: 692-700. 
23 Chew CYC, Hecht HS, Collett JT, McAllister RG, Singh $B N$. Influence of severity of ventricular dysfunction on hemodynamic responses to intravenously administered verapamil in ischemic heart disease. Am J Cardiol 1981; 47: 917-22.

\section{Résumé}

Treize patients ayant une bonne fonction ventriculaire gauche et subissant un pontage aortocoronarien ont été étudiés afin de déterminer les effets cardiovasculaires de la vérapamil, $75-150 \mu \mathrm{g} \cdot \mathrm{kg}^{-1}$, après une large dose $\left(100 \mu \mathrm{g}^{-1}\right)$ de fentanyl avec pancuronium pour le relâchement musculaire. Les patients ont continué leur médications cardiovasculaires habituelles jusqu'au début de la chirurgie ceci incluant les nitrates, les bétabloqueurs, el la nifedipine. $L$ 'anesthésie avec du fentanyl a été associée à une diminution de la pression artérielle moyenne, résistance vasculaire systémique, le travail du ventricule gauche indexé, et les taux de catecholamines circulantes. Les valeurs moyennes n'ont pas été altérées davantage par l'administration de vérapamil, mais certains patients ont répondu par la diminution additionnelle modeste de la tension artérielle et de la résistance vasculaire systémique. L'index cardiaque, cependant, est resté bien maintenu. Le taux de catecholamine plasmatique est resté bas après verapamil sous des conditions de l'étude. Ainsi, chez les patients avec une bonne fonction ventriculaire gauche les doses clinique. ment significatives de vérapamil ont été bien tolérées même en présence d' anesthésie incluant de large doses de fentanyl pouvant déprimer les catecholamines circulantes. 